DOCUMENTA

\title{
CHEFE JAGUAR, CHEFE ÁRVORE: AFINIDADE, ANCESTRALIDADE E MEMÓRIA NO ALTO XINGU*
}

Carlos Fausto

\begin{abstract}
Apresentação
Neste número de Mana, é com imenso prazer que trazemos a público, na seção Documenta, a conferência proferida pelo professor Carlos Fausto durante seu concurso para Professor Titular do Departamento de Antropologia do Museu Nacional/UFRJ.

A conferência teve lugar no Museu Nacional, no dia 21 de novembro de 2016, na sala Lygia Sigaud, tendo sido acompanhada pela banca examinadora do concurso, formada pelos professores Luiz Fernando Dias Duarte, Roberto DaMatta, Manuela Carneiro da Cunha, Sylvia Caiuby Novaes e Ronaldo Vainfas e por uma audiência repleta, composta por colegas, alunos, ex-orientandos e demais interessados.

Toda conferência de titular é uma oportunidade singular de perceber qual a releitura de sua obra proposta pelo candidato depois de um percurso significativo de trabalho. Convidando os ouvintes / leitores a visitar o Alto Xingu, Fausto percorre temas que têm caracterizado seus estudos etnológicos. Inicialmente apresentando um panorama da pré-história xinguana e de sua formação como um sistema multiétnico e plurilíngue, cuja identidade regional é produzida através da vida cerimonial, ele procura demonstrar como o xamanismo e a chefia se encontram, já que os rituais estabelecem mediações sociopolíticas e cosmopolíticas, e seu patrocínio é feito por aqueles que possuem o estatuto de chefe.
\end{abstract}


Depois de explorar uma série de aspectos da chefia xinguana (quem é o chefe, como alguém se torna chefe, como a chefia associa-se, miticamente, à árvore umiri, como há uma dupla constituição, animal e vegetal, dos chefes), o autor passa a analisar o ritual do Quarup. Ao debater a efígie enquanto um artefato, traz à discussão questões como representação e presença; semelhança e evocação; memória, passado e futuro; transmissões intergeracionais de nomes, prestígios e cargos. Isso tudo com vívidas descrições de cenas.

Assim, ao produzir uma delicada análise sobre as "teorias nativas" da chefia xinguana, a conferência se desdobra nos campos da antropologia dos rituais, da antropologia da política, da antropologia da arte e da cultura material, da antropologia visual, e do diálogo entre antropologia social, arqueologia, história e linguística. Como a carreira do próprio professor.

\section{Os editores}


Para Afukaká e Mike, por tantas conversas

Era junho de 2015. Após dois dias subindo o rio Xingu desde Altamira, estávamos para aportar na aldeia Apyterewa-Parakanã, onde ofereceríamos uma oficina de vídeo. No barco, vinham comigo dois amigos kuikuro, parceiros de longa data: Takumã e Mahajugi. Takumã já viajou muito, não apenas pelo Brasil, como também pela Europa e Estados Unidos. Sempre cuidadoso e atento às diferenças culturais, antes que o barqueiro desligasse o motor, perguntou-me em português:

- Carlos, como se chama o chefe que vai nos receber?

- Taku, não tem chefe aqui.

- Como assim? Não tem chefe?

- Ué, não tem chefe.

- Mas, então, quem vai nos receber?

A perplexidade de Takumã diante da ausência do chefe nada tem a ver com modelos europeus de chefia - não é uma dessas anedotas que emergem dos documentos coloniais, nas quais os conquistadores buscam em vão um principal para negociar. Ela exprime, antes, um contraste objetivo entre um mundo no qual chefes são infactíveis e outro em que são a condição mesma de haver um mundo. Esse contraste também me surpreendeu - embora ao inverso - quando cheguei aos Kuikuro pela primeira vez, após uma longa experiência de pesquisa entre os Parakanã. ${ }^{1}$

Nesta conferência, pretendo partilhar um pouco do que aprendi sobre a chefia xinguana, de modo a reinserir em nosso imaginário sobre a Amazônia - passada e presente - formas sociopolíticas deixadas de lado por um modelo que, remontando ao famoso dito de Gândavo, consolidou-se no Handbook of South American Indians, ganhou forma filosófica em Clastres e chegou até a etnologia contemporânea sem muitos reparos. ${ }^{2}$ É preciso matizá-lo, lançando um olhar cuidadoso sobre a variabilidade interna às chamadas Culturas da Floresta Tropical. Hoje, porém, não desenvolverei um argumento teórico; tampouco apresentarei um quadro comparativo. Prefiro convidá-los a imergir em um só caso etnográfico, esperando que desta experiência aflore uma nova sensibilidade. 


\section{Escala: a pré-história xinguana}

O Alto Xingu é uma zona de transição entre a savana e a floresta amazônica, banhada pelos formadores do rio Xingu. Aí se constituiu um sistema multiétnico e plurilíngue, cuja origem remonta ao século 9 d.C., quando uma indústria cerâmica distintiva e aldeias circulares aparecem na região. ${ }^{3}$ Essa cerâmica é uma variante da tradição barrancoide amazônica, geralmente associada a povos de língua arawak. A hipótese de que esses colonizadores eram, de fato, arawak, é reforçada pela distribuição contínua de outros povos da mesma família linguística ao longo de toda a periferia meridional da Amazônia, desde Llanos de Mojos, na Bolívia, até o Xingu.

Uma vez instalada na região, essa população aumentou consideravelmente nos séculos seguintes. Em meados do século 13, dá-se uma mudança de escala: grandes aldeias de até 40 hectares (dez vezes maiores do que as atuais) passam a dominar a paisagem. Algumas dessas aldeias eram cercadas por estruturas defensivas - valetas de 5 metros de largura e 4 de profundidade, estendendo-se por até 2,5 quilômetros em torno da área habitada. As aldeias fortificadas estavam interligadas a outros assentamentos de médio e grande porte por meio de estradas de até 20 metros de largura e 5 quilômetros de extensão. É possível supor que os conjuntos de aldeias interligadas definissem unidades políticas autônomas, no interior de uma constelação regional multicêntrica.

Em meados do século 17, esse sistema, que Michael Heckenberger denominou "galáctico", entrou em colapso, possivelmente devido a doenças introduzidas pela Conquista que, mesmo sem contato direto, já se espalhavam por toda a Amazônia. Esse colapso é marcado pelo abandono das estruturas coletivas e pelo surgimento de sítios de menor tamanho, semelhantes aos observados por Karl von den Steinen, no final do século 19. No momento da chegada de Steinen, o Xingu já era um complexo multiétnico e plurilíngue, composto por povos tupi, karib e arawak, além dos Trumai. Como teria surgido esse complexo?

Os alto-xinguanos compartilham uma mesma versão para explicar a formação desse sistema. ${ }^{4}$ Identificam como autóctones os Wauja e os Mehinaku (povos arawak), junto com Kuikuro, Kalapalo, Nahukwá e Matipu (povos karib). Consideram os demais recém-chegados, que adentraram a região em tempos históricos e adotaram o modo de vida xinguano. Dentre os que ali chegaram nos séculos 18 e 19, contam-se dois povos tupi (Kamayurá e Aweti), um povo arawak (Yawalapiti), além dos Trumai. A versão arqueológica dessa história coincide basicamente com as narrativas locais, embora subsistam dúvidas quanto ao momento de chegada e incorporação dos povos karib e dos Yawalapiti. ${ }^{5}$ 
A entrada dos recém-chegados no sistema é narrada como resultado da adoção voluntária de um pacote cultural, que inclui uma dieta proibindo a carne de caça, uma estrutura específica de casa e aldeia, uma certa decoração corporal, um comportamento pacífico, o respeito a chefes e a participação em um complexo mítico-ritual comum. Sabe-se, porém, que a cultura xinguana contemporânea não resultou da simples adaptação unilateral a essa matriz. Muitas das manifestações rituais atuais, por exemplo, foram apropriadas de povos xinguanizados, sendo que mesmo o Quarup exibe evidências do processo histórico de hibridização.

Se o fluxo de ideias conduziu a uma morfologia sociocultural similar, as diferenças linguísticas junto com especialidades artesanais serviram como diacríticos internos ao sistema. O plurilinguismo xinguano contrasta com a homogeneização linguística característica de expansões imperiais. Ao contrário do que ocorreu nos Andes, com a difusão do aymara e do quíchua, nenhuma língua franca emergiu na região até a entrada do português. Antes que uma comunidade linguística, produziu-se uma comunidade moral por meio da participação em uma economia político-ritual comum. Como sugeriu Menezes Bastos, o ritual foi, e ainda é, a língua franca xinguana.

\section{Articulações xamânico-políticas}

A vida cerimonial é o mecanismo-chave de produção da identidade regional, ao mesmo tempo em que expressa a autonomia de cada unidade política: uma aldeia permanece um satélite daquela da qual se separou até enviar ou receber mensageiros, convidando ou sendo convidada a participar de festas intertribais. ${ }^{6}$ Hoje, há cerca de 15 rituais no Alto Xingu. Todos eles estruturam-se em torno de um conjunto de cantos, uma ou mais narrativas míticas e uma rotina coreográfica precisa. Alguns desses rituais reúnem diferentes povos, enquanto outros são internos a uma única unidade política. No caso dos primeiros, ocorre sempre uma luta esportiva entre anfitriões e convidados (no passado, havia também competições de corrida e jogos de bola). A estrutura organizacional básica é sempre a mesma: há um "dono-mestre" (oto), responsável por prover os alimentos, e três a seis pessoas que funcionam como coordenadores, mediando a relação entre a coletividade e o dono. Esses coordenadores são aqueles que, inicialmente, solicitaram ao futuro dono assumir a maestria do ritual.

Alguns poucos rituais estão diretamente associados à chefia, tais como a cerimônia de furação de orelhas e o rito funerário do Quarup. Os demais vinculam-se intimamente ao xamanismo e aos processos de doença 
e cura. A via mais comum para tornar-se o dono de um ritual é ter a alma capturada por espíritos (itseke). Durante a terapia, os xamãs identificam os responsáveis pela doença e promovem uma sessão coletiva de cura na qual várias pessoas imitam os espíritos, atraindo-os para a aldeia. Após a sua recuperação, o doente é chamado à praça, onde especialistas rituais dizem-lhe que desejam "copiar" ou "imitar" (akuãpütelü) os espíritos que lhe causaram a enfermidade. Ao consentir, o ex-paciente torna-se o dono do ritual ao qual correspondem esses espíritos, devendo alimentá-los por anos a fio. Assim, reconfigura-se a relação patogênica: os espíritos predadores passam à condição de xerimbabos (tolo) do doente. A partir daí, eles o protegerão - claro, desde que sejam bem alimentados e alegrados com a realização de suas festas.

Os rituais fazem a mediação sociopolítica entre humanos e a mediação cosmopolítica entre humanos e não humanos, transformando uma doença privada em um assunto público produtivo. Embora a maestria de um ritual dependa das vicissitudes das patologias e dos diagnósticos, a maioria das pessoas que efetivamente a assume possui o estatuto de chefe. Patrocinar um ritual significa fornecer comida não só à comunidade local e aos convidados humanos, como também aos alterumanos que comparecem à festa. Essa posição de alimentador é tipicamente uma de autoridade: quem alimenta cria um vínculo assimétrico com quem é alimentado, vínculo frequentemente caracterizado na Amazônia como aquele entre um dono e um xerimbabo. Toda execução ritual, portanto, marca e produz publicamente o status de chefe, atualizando-o e magnificando-o. ${ }^{7}$

Mas, afinal, o que conta como um chefe no Alto Xingu?

\section{Nascer e tornar-se chefe}

Todas as línguas xinguanas têm um termo para designar uma condição social particular, geralmente traduzida na literatura como a de um "chefe", embora talvez fosse melhor glosá-la como a de um "nobre". ${ }^{8}$ Em karib, o termo mais comum é anetü, cujo plural é anetão. A categoria implica uma condição dada pelo nascimento: anetão são filhos e filhas de anetão. Ponto. Mas há gradações: primeiro, a chefia de alguém é dita ser "mais pesada" (titeninhü) quando provém de ambos os lados (materno e paterno); segundo, as crianças primogênitas são, em princípio, mais chefes do que seus irmãos mais novos - fato marcado (e ao mesmo tempo produzido) por uma série de atos, tais como uma couvade mais longa ou a transmissão dos nomes mais valorizados. 
Outras gradações resultam da atualização, durante a vida, dessa condição dada pelo nascimento. Isto depende tanto da personalidade quanto da aleatoriedade de qualquer biografia. Assim, por exemplo, um filho primogênito propenso a irritar-se logo é posto de lado em favor de seu irmão mais novo. Um chefe deve ter a confiança de sua comunidade, e esta confiança é obtida por atos generosos e uma postura cordial. Tais qualidades definem a própria condição kuge - um termo que significa "humano", "pessoa moral", mas também "chefe", dependendo do contexto. No entanto, é preciso notar, um anetü excessivamente tímido nunca exercerá uma função executiva, uma vez que, como veremos, os verdadeiros líderes são também jaguares.

Homens e mulheres têm uma chefia igualmente legítima. Os homens, porém, têm mais chances para atualizar e magnificar essa condição, a começar pelo fato de as mulheres não poderem participar das reuniões na praça central. Além disso, entre os Kuikuro (diferentemente dos Arawak), não há nenhum equivalente feminino à cerimônia masculina de furação de orelhas. Nesta última, há seis posições ranqueadas internamente que conferem prestígio aos noviços, sendo que a primeira delas constitui uma marca indelével de liderança, especialmente se um osso de jaguar for usado como perfurador.

Para se tornar um chefe influente é preciso, ademais, ficar conhecido além da própria comunidade. A magnificação depende da circulação de um nome no sistema regional. Só assim um chefe tornar-se-á "falado" (tikaginhü), e o seu nome perdurará no tempo e se expandirá no espaço. Por isso, o ato que marca definitivamente a feitura de um chefe como líder de um povo consiste em designá-lo como um "chefe dos convidados" (hagito anetügü) em um festival intertribal. Nessas ocasiões, três anetü, hierarquizados internamente, são formalmente recebidos pelos anfitriões. São eles que devem cuidar de "seu pessoal" (isandagü), alimentando-os com a comida que recebem dos patrocinadores da festa. Durante a execução ritual, devem permanecer sentados em bancos - um ato passivo que sinaliza seu status. Por isso, são denominados "os que vão sobre o banco" (tahaguhongo).

Uma outra via para tornar-se "falado" no sistema regional são as competições de luta que, como vimos, ocorrem nos rituais intertribais. Essas competições opõem os dez melhores lutadores da aldeia anfitriã aos dez melhores lutadores de cada povo convidado. Um verdadeiro campeão, conhecido como kindoto ("mestre de luta"), adquire um notável prestígio. Mesmo sem ascendência de chefia, a ele é permitido portar os adornos de jaguar exclusivos de chefes importantes, bem como ser comemorado em um Quarup após a sua morte. Note-se, porém, que essa condição não é transmissível aos seus filhos. 
Até recentemente, o desempenho como lutador era um dos principais fatores a determinar a ascensão de chefes a funções executivas - não por acaso, muitos dos que cumpriram esse papel no último quartel do século 20 foram, de fato, campeões de luta na juventude. O principal chefe kuikuro, por exemplo, é genealogicamente meio-chefe (heinongo) - sua chefia provém apenas do lado materno. Este fato foi compensado por sua primogenitura, pois ele recebeu o principal nome de seu avô materno, um conhecido chefe do passado. Embora ranqueado em quinto na cerimônia de furação de orelha, graças à sua personalidade e à sua condição de kindoto, terminou por se tornar o principal chefe executivo, o "dono da praça central" (hugogo oto). Esta posição decorre de seu papel como aquele que profere o discurso formal de recepção dos mensageiros vindos de outras aldeias, discurso que somente os chefes "verdadeiros" (hekugu) têm o direito de aprender, executar e transmitir. No seu caso, como o avô morreu jovem, ele teve que aprendê-lo com outro chefe, a quem pagou pelo ensinamento. O hugogo oto é também aquele que tem a primeira palavra para iniciar uma deliberação entre homens adultos na praça. Nessas ocasiões, dirige-se sempre ao seu próprio pessoal como "crianças" (kangamuke), independentemente da idade, aparecendo como o mestre-pai (oto) de toda a sua comunidade.

Chefes podem também tornar-se donos de outras estruturas da aldeia, tais como a casa dos homens, o caminho ritual, a barragem de pesca, e assim por diante. Essas estruturas devem ser atribuídas a uma pessoa pela comunidade, não devendo permanecer res publica. Para os Kuikuro, o que é tatutolo engü ("coisa de todos") não é responsabilidade de ninguém e, portanto, é deixada em estado de completo abandono. Por isso, a comunidade atribui essas estruturas a uma pessoa, que deve ser capaz de mobilizar o trabalho coletivo para construí-la e conservá-la, sempre provendo os participantes de comida. Na maioria dos casos, esse trabalho está associado a um ritual, de tal modo que os donos de certas estruturas são também donos de certos rituais. Assim, por exemplo, a construção da casa dos homens (kuakutu) é acompanhada pela música das flautas sagradas, as quais têm seus próprios donos - tanto um espírito quanto um humano. Em todos os assuntos públicos, uma série de relações de maestria e de alimentação, entre humanos e entre humanos e espíritos, se intersectam. A vida ritual surge, assim, como o eixo em torno do qual a autoridade política e o xamanismo se articulam inextrincavelmente. 


\section{A casa do chefe e o umiri}

Uma das maiores distinções que uma comunidade pode conceder a um chefe é construir-lhe uma casa, conhecida como tajühe. Não se trata de uma casa comum. Em primeiro lugar, ela deve ser erguida pela coletividade sob a coordenação de seis pessoas, que solicitam ao chefe, em nome de todos, para construí-la. Em segundo lugar, ela é sempre erguida em associação com rituais específicos, mobilizando, uma vez mais, a rede de maestria cosmopolítica. A terceira característica distintiva é sua singularidade estética: motivos gráficos são aplicados a painéis fixados no telhado e na parede interna faceando a porta de entrada. Menos frequentes - e mais impressionantes - são as três figuras (um jaguar, uma sucuri e um sapo) esculpidas em terra, que se erguem no centro da casa. Todo o conjunto destina-se a fazer da casa um objeto de respeito-temor (itsanginhü, cuja raiz itsangi implica tanto perigo como deferência).

Embora a casa seja do chefe - e ele ou ela seja seu "dono" (oto) - não raras vezes os Kuikuro dizem que a tajühe é de quem a construiu - isto é, da coletividade. Chefes gostam de contar quão difícil é corresponder à expectativa de generosidade das pessoas, pois as portas devem permanecer abertas, qualquer um pode entrar a qualquer hora e deve sempre haver comida a oferecer. A maioria das pessoas, porém, afirma que nem se atreveriam a lá entrar. O respeito-temor é, pois, um duplo mecanismo de controle: dos chefes que devem mostrar-se generosos, e de "seus seguidores" que devem demonstrar deferência.

Outra característica distintiva da tajühe - e este é o quarto aspecto - é que ela deve ser construída com um tipo de madeira especial: o umiri (Humiria balsamifera var. floribunda), considerado o anetü de todas as árvores. ${ }^{9}$ Embora seja uma das madeiras mais densas e pesadas da região, não pode ser utilizada como material construtivo em uma casa comum. Ela só pode ser usada na casa do chefe, cujos batentes das portas, bem como os dois pilares principais (nos quais se amarram as redes) devem ser de umiri. Esses pilares são ainda decorados com um grafismo especial, o motivo do Quarup, que não pode ser aplicado no corpo humano.

O enorme esforço coletivo necessário para levar postes de até 8 metros de altura, por até 5 quilômetros, desde a floresta até a aldeia - principalmente quando não havia caminhões nem tratores - torna tangível a autoridade do chefe e a confiança nele depositada pela comunidade. A própria materialidade da madeira indexa a qualidade da chefia: o umiri é tão pesado quanto um chefe é dito ser. O caráter retilíneo do tronco funciona, ainda, como uma imagem apta da desejada continuidade intergeracional das linhas de chefia. Por fim, a árvore também remete a um mito, para o qual me volto agora. 


\section{As mulheres de madeira e o marido jaguar}

Vou resumir drasticamente a narrativa, que é o mito axial do Alto Xingu e uma variante da saga pan-americana dos gêmeos. ${ }^{10}$ Entre os Kuikuro, ela começa com o demiurgo Kuãtüngü coletando uma fibra vegetal nos arredores da aldeia dos Jaguares. O chefe jaguar Enitsuegü (um nome que significa "hiperinimigo") apanha-o em flagrante. Para não ser devorado, Kuãtüngü oferece suas filhas em casamento, mas ao voltar para casa, muda de ideia. Fabrica, então, pares de mulheres com diferentes tipos de madeira. Dependendo da versão, o número de pares varia, mas em todos elas há sempre um par feito do nosso já conhecido umiri e outro feito de hata, uma madeira mais leve.

O mito conta em detalhes como Kuãtüngü fabricou o corpo dessas mulheres - seus cabelos, dentes, orelhas, vagina - fazendo experiências com diferentes materiais. Uma vez prontas, ele as animou com seu sopro-reza, e as enviou para a aldeia dos Jaguares. Durante a longa jornada, elas fazem sexo com diversos animais e a maioria acaba por se perder. Apenas aquelas feitas de umiri chegam ao destino final e se casam com Enitsuegü. Seus nomes eram Tanumakalu (um nome arawak) e Itsangitsegu (um nome karib que parece conter a raiz itsangi, " respeito-temor").

Itsangitsegu logo engravida de gêmeos, mas é morta pela própria sogra. Ainda assim, Sol e Lua vêm ao mundo. Sol, o mais velho, chama-se Tãugi (possivelmente uma forma abreviada de tãuginhü, "mentiroso") - ele é, sem dúvida, um trickster; já Lua recebe um nome arawak, Aulukumã, que designa a forma hiper do cachorro-do-mato. À imagem do pai, eles nascem com uma cauda de felino, mas Tanumakalu apressa-se em cortá-la, desfabricando um corpo-jaguar. Os gêmeos crescem rapidamente sem saber da morte da mãe, acreditando-se filhos de Tanumakalu. Um dia, porém, são flagrados por Inambu enquanto roubavam amendoim de sua roça. Em um ato de incontinência verbal, Inambu conta-lhes a verdade sobre a mãe. Sol e Lua saem à sua procura e a encontram no topo da casa.

A mãe estava em um estado liminar entre a vida e a morte - fraca demais, emaciada demais, difícil demais de ser cuidada. Os gêmeos decidem não revivê-la, preferindo deixá-la morrer definitivamente. Dá-se a primeira morte e o primeiro enterro da história, cuja rotina ritual é até hoje repetida quando um chefe morre. Um ano depois, Sol e Lua realizam um grande festival, no qual homenageiam sua mãe, figurando-a por meio de uma efígie feita de umiri - a mesma madeira com que seu pai a havia fabricado. O mito narra, assim, não só a origem da mortalidade humana, como também a de uma forma fraca de imortalidade, que consiste em ser comemorado em um Quarup. Desde então, sempre que um chefe morre, uma efígie é feita em sua homenagem. 


\section{Eviscerando o jaguar}

O ciclo do Quarup começa muito antes da fabricação da efígie. ${ }^{11}$ Seu ponto de partida é o pedido feito à família para enterrar o cadáver no centro político e ritual da aldeia: a praça. Se a família concordar, estará aceitando também realizar o festival funerário um ano depois. Não apenas o local de sepultamento é distinto, mas também a forma da cova. Entre o Kuikuro, fazem-se dois furos conectados por um túnel, dentro do qual o corpo pintado e decorado, envolvido em uma rede, é suspenso.

Cinco dias após o enterro, a aldeia deixa o luto por meio de uma cerimônia de lavagem. Até lá, ninguém vai ao centro da aldeia, fala alto ou faz piadas. Um silêncio respeitoso, entrecortado pelos lamentos provenientes da casa do falecido, domina a paisagem sonora. A cerimônia de lavagem começa com um conjunto de canções, consideradas extremamente perigosas, denominadas "o destripar do jaguar" (ekege tehukipügü). ${ }^{12}$ Os cantos são em arawak e incompreensíveis para os Kuikuro que, no entanto, conhecem a narrativa de sua origem. Conta-se que há muito tempo um casal adotou um jaguar como xerimbabo, mas, ao crescer, ele acabou por comer a filha deles. O animal fugiu e passou a devorar todos os artefatos que encontrava - redes, panelas, armas - aterrorizando toda uma região. O povo da aldeia de Magakani decidiu, então, treinar quatro meninos como "mestres do arco" (tahaku oto), para que pudessem um dia matar o grande predador. Ao final da narrativa, eles conseguem abater o jaguar e trazem seu cadáver para a aldeia. Começam a destripá-lo, extraindo e lavando todos os artefatos que ele havia comido em vida, ao mesmo tempo em que entoam as canções que, hoje, servem para lavar a comunidade e encerrar o período mais estrito do luto.

O "destripar do jaguar" é um rito para extrair um povo-artefato do interior de seu chefe morto. ${ }^{13}$ A partir desse momento, o chefe não contém mais em si o "seu pessoal" (isandagü). Ele foi eviscerado e será progressivamente transformado em um antepassado vegetal, cuja última etapa é sua fabricação como efígie. Boa parte da biografia de um chefe é marcada pela produção de um corpo-jaguar (e, paradoxalmente, de uma disposição antijaguar). Por meio de sua história ritual, um anetü vai sendo fabricado à imagem de um felino: como noviço, suas orelhas são perfuradas por outro chefe que o ataca com um osso afilado de jaguar; como jovem lutador, ele se move e esturra como um formidável predador; como dono de ritual, ele porta o colar de garras, o cinto e o chapéu de uma onça pintada; como chefe executivo, a comunidade constrói-lhe uma casa onde esculpe uma estátua de jaguar; como dono da praça, ele profere discursos formais, dirigidos à comunidade no início da manhã e no final da tarde, conhecidos respectiva- 
mente como "Gavião" e "Jaguar". Imagino que se Tanumakalu não tivesse cortado a cauda dos Gêmeos, talvez fosse menos laborioso, hoje, fabricar chefes-jaguares.

Nesse aspecto, os chefes xinguanos não destoam dos demais donos-mestres que povoam a Amazônia, a maioria deles também identificada a jaguares. Tampouco destoam em seu caráter dupla-face: aos olhos de seus filhos, são pais protetores; aos olhos dos outros, afins predadores. Faces instáveis porém, como bem sabem os xinguanos, que mantêm os seus chefes sob constante vigilância, examinando-os minuciosamente em busca de sinais de uma disposição predatória. O que é menos comum - embora não inaudito em outras partes da Amazônia - é como esse jogo de dupla-face, dessa figura quimérica feita de afinidade e consanguinidade, resolve-se quando de sua morte. O ritual do Quarup desfabrica o jaguar a fim de elicitar o chefe como um antepassado vegetal - não mais como um híbrido de Enitsuegü e Itsangitsegu. Sua parte-inimigo é extraída, para que ele possa sustentar uma imagem de continuidade intergeracional. A afinidade cede espaço à ancestralidade, a inimizade cede lugar à memória de linhas e nomes comemorados.

\section{O chefe-efígie}

Passado um ano do enterro na praça, já às vésperas da grande festa, homens adultos vão à floresta para cortar uma árvore de umiri. Geralmente, basta uma planta para confeccionar três efígies: um chefe nunca é comemorado sozinho, devendo ser ladeado por "seus seguidores". A seção inferior do tronco é reservada ao chefe principal, enquanto as seções superiores destinadas aos demais. Cortar uma árvore de umiri envolve novos perigos, uma vez que ela mesma possui um dono (oto) poderoso, que deve ser apaziguado. Por isso, xamãs passam mingau de pimenta e sopram fumaça de tabaco nas extremidades seccionadas, enquanto o dono do ritual profere uma fala formulaica, pedindo-lhe que não lhes faça mal.

Jovens carregam os troncos até a entrada da aldeia, onde são depositados. Flocos de algodão são aplicados à seiva que exala das extremidades. $\mathrm{O}$ fluxo da seiva é o choro do espírito-dono e um mau presságio para os vivos. É imperativo gerir o relacionamento com o dono do umiri, que é consubstancial ao chefe morto, e cuja matéria servirá para figurá-lo. A conexão entre o espírito e a árvore tem de ser afrouxada, de modo que uma nova conexão seja fabricada entre o falecido e sua efígie. Esse processo de conexão-desconexão, contudo, é instável. Surge, assim, uma nova zona de indeterminação, desta 
feita, entre o chefe morto e o dono do umiri. Durante todo o ritual, os xamãs permanecerão atentos à presença deste último, pedindo-lhe repetidamente que "não nos chore".

Chega, enfim, o grande dia. No início da manhã, os familiares do morto, os donos do ritual, são levados à praça, onde seus cabelos são cortados e seus corpos são pintados. Três deles, todos homens, presidirão o ritual, mantendo uma rígida postura ereta e estática, como a de um tronco retilíneo. Eles se apresentam assim, publicamente, como imagens antecipadas de seu próprio destino efigial.

Os troncos são carregados até a praça, acompanhados por dois especialistas que entoam as mesmas rezas usadas no enterro um ano antes. Comprime-se o tempo entre o sepultamento e a festa: os troncos são transportados como cadáveres, mas em vez de serem enterrados deitados, são fincados na vertical, revertendo - mesmo se apenas por um momento - a mortalidade humana. Uma vez fixados, procede-se à sua pintura. Padrões diferentes são usados para efígies masculinas e femininas. Estas últimas são decoradas com motivos comuns de pintura corporal, enquanto as primeiras recebem um motivo exclusivo que só pode ser aplicado sobre artefatos de umiri. Composto de um quadrado preto circunscrito por outros quadrados, o motivo é conhecido como tihigu angagu, "pintura de jenipapo da liana tihigu", com a qual se fazem as armadilhas de pesca (cujo trançado configura um gradeado quadrado). Não possuo uma exegese nativa para esse fato, mas não resisto a associá-lo à noção de Gell dos objetos de arte como armadilhas (e das armadilhas como objetos de arte). Como veremos, a agência das efígies funda-se em sua capacidade passiva de atrair mimeticamente a alma-duplo do morto e de servir-lhe como imagem tangível.

Depois de pintadas, as efígies permanecem no centro da aldeia esperando que dois cantores entoem os cantos auguhi. Os parentes dos homenageados saem de suas casas, levando cintos de algodão, colares de conchas e diademas de penas, com os quais adornam as efígies. Neste momento, muitas pessoas se agacham e pranteiam o morto, tal como haviam feito durante o enterro. Do ponto de vista da família, a efígie é o morto e deve ser pranteada até a manhã seguinte. Do ponto de vista dos especialistas rituais, contudo, ela não é apenas um morto, pois parece ganhar vida e tornar-se gente.

\section{O duplo do duplo}

Jamais ouvi alguém dizer que a alma-duplo do falecido (akuãpe) vem habitar a efígie. ${ }^{14}$ Diz-se antes que ela desce do céu e fica ao lado do tronco durante o ritual. Nesse sentido, a akuãpe é a dobra invisível de um duplo visível (a própria efígie), antes do que um princípio de animação. Após a 
morte, a alma-duplo (akuã) torna-se a dobra invisível de um corpo que já não mais existe. Por isso, passa a ser denominada akuãpe, o sufixo "-pe" marcando a disjunção: o duplo, a alma, a imagem, em suma a akuã, continua a existir, mas aquilo de que era a dobra invisível (o corpo vivo) não existe mais. O que o ritual permite é a presença simultânea da akuãpe e de seu novo corpo, desta feita artefatual. Não se postula, porém, um ensoulment do artefato, mas a presença de dois duplos - um tangível, outro intangível - lado a lado. A efígie substitui o corpo ausente, tornando-se a âncora da akuãpe, que é atraída do céu e mantida momentaneamente na terra.

Uma das expressões com que se denomina uma efígie é X-hutoho (X sendo aqui o nome do morto). Hutoho designa qualquer expressão visual figurativa com evocação mimética, em duas ou três dimensões. Aplica-se a esculturas, miniaturas e efígies, bem como a desenhos figurativos e à fotografia (mas não à imagem em movimento). Todo hutoho age como uma espécie de isca, pois a semelhança convoca a presença. Assim, por exemplo, os feiticeiros moldam estatuetas de queixada e enterram-nas na roça de seus inimigos, a fim de atrair uma vara de porcos para comer a mandioca. Com uma disposição mais benéfica, podem-se confeccionar também pequenos peixes de argila e deixá-los dentro de armadilhas de pesca, a fim de favorecer a captura. Ou ainda, durante o ritual do pequi, esculpem-se diversos pássaros em madeira, com destaque para o beija-flor que é o dono (oto) dos pequizais, a fim de que compareçam à festa. Em todos esses contextos - é mister notar - os artefatos miméticos hutoho não funcionam por si sós, mas precisam ser ativados por palavras rezadas, murmuradas, sopradas.

Outro interessante artefato figurativo é uma boneca feita pelos xamãs para recuperar a alma-duplo de um humano roubada por um espírito. Embora seja uma representação perfeitamente antropomórfica, essa boneca não é chamada de kuge hutoho, isto é, "imagem figurativa de uma pessoa humana". Em vez disso, é referida simplesmente como akuã ("alma", "duplo", "imagem"). Durante a sessão de cura, um dos xamãs fabrica a akuã e a insufla com seu sopro-reza para animá-la. Em seguida, fuma até desmaiar, quando então localiza a akuã raptada. Negocia a sua libertação, pagando aos espíritos com bens de luxo oferecidos pela família que o contratou. A akuã do paciente é, então, transferida para a akuã artefatual e dela, enfim, para o doente. Não se trata, porém, do retorno de uma unidade substantiva e indivisível do mundo dos espíritos ao paciente humano. Toda doença causada por espíritos distribui a pessoa, de tal modo que ela passa a existir em ambos os mundos simultaneamente. Mesmo quando o paciente recupera a sua akuã, esta continua ligada a seus captores, de tal modo que ele passa a ter uma dupla existência aqui e alhures (e assim sucessivas vezes 
sempre que adoecer). Não obstante, até a morte da pessoa-em-seu-próprio-corpo (tihühokolo), há um vínculo vital entre ela e suas múltiplas réplicas - ou seja, a pessoa-viva conecta todas as suas dobras, que se dispersarão quando de sua morte.

Essa terapia xamânica é chamada akuãtelü, uma forma verbalizada do nome akuã que pode ser traduzida como "fazer um duplo". O ato de fabricar a efígie do Quarup, especialmente no discurso ritual, é também referido por uma expressão semelhante: akuãpütelü, onde -pü- conota uma condição passada, indicando que se trata do duplo de algo que não mais existe (o corpo vivo). Assim, fabricar a efígie é fazer um novo duplo, uma nova akuã a efígie é uma cópia que atrai a alma-duplo do falecido (ou mais exatamente, uma de suas réplicas, a qual se reputa viver na aldeia celeste). De imagem sem protótipo, a akuãpe torna-se o protótipo de um artefato e vice-versa. Há um engano produtivo nesse jogo de duplicações. Do ponto de vista da própria akuãpe, a efígie é seu protótipo corporificado (embora os vivos saibam que se trata apenas de uma isca manufaturada). Já do ponto de vista dos vivos, a akuãpe é o protótipo intangível da própria efígie, algo que só é possível vislumbrar se o artefato for, de algum modo, animado.

\section{A animação do umiri}

A visão dos xamãs sobre esses assuntos é, como se poderia esperar, sempre mais elaborada do que a dos leigos. Costumam afirmar que a efígie torna-se "humana" (kuge) durante o ritual. A forma verbal empregada aqui é sukugetilü, que serve para dizer, por exemplo, que um espírito adquiriu forma humana ou, ainda, que uma criança adquiriu as disposições morais de uma pessoa adulta. Pedi a dois xamãs que identificassem o momento exato do ritual em que essa transformação ocorre. Eles apontaram vários momentos em um crescendo: pela manhã, quando os troncos são pintados; no começo da tarde, quando as famílias os adornam ricamente e se reúnem para pranteá-los; no meio da tarde, quando os auguhi são cantados. Aliás, esses cantos são mesmo designados tita egikaginetoho, "aquilo que serve pra despertar o topo do tronco". A expressão contém o verbo kagine que significa "assustar", e remete a um resfolegar, um respirar rapidamente pela boca, tornando à vida novamente.

À noite, dois cantores de cada aldeia vêm à praça a fim de cantar os auguhi para as efígies. Este é o clímax da primeira parte do ritual, após o que a maioria das pessoas vai dormir. Somente parentes próximos, especialistas rituais e antropólogos permanecem ao lado das efígies, iluminadas pelo 
fogo lento e ardente dos feixes de lenha. Antes do amanhecer, os auguhi são cantados pela última vez. Este é o momento mais solene e perigoso, pois se arrisca a ver o morto como uma pessoa viva, adornada como a efígie. A esposa de um xamã contou-me que isso de fato aconteceu, não faz muito tempo, na aldeia kalapalo de Aiha. Um homem viu sua falecida irmã, que tinha sido feita efígie, como se fosse uma pessoa de fato. Ele não a viu como artefato, nem como duplo imaterial, mas como verdadeiro kuge. Ver o que não é suposto ser visto é ahintsa, isto é, um mau presságio. Naquele dia, o ritual foi abortado. Não houve sequer as lutas entre anfitriões e convidados. Pela manhã, todos haviam partido. Cinco dias depois, o homem que vira viva sua irmã morta não mais vivia.

Na maioria dos casos, porém, as regras constitutivas do ritual e os atos protetivos dos xamãs garantem um final feliz. ${ }^{15} \mathrm{O}$ ritual não busca fundir a pessoa morta e a efígie - isto só acontece quando algo sai errado e, como vimos, pode ser fatal. O que se quer é criar uma zona de indeterminação, flertar com a possibilidade de animação, mas não ressuscitar os mortos. O ritual produz um estado de incerteza no qual a alma-duplo do morto apresenta-se de forma visível como artefato. Trata-se de convocar sua presença sem anular a distância - mesmo que infinitesimal - entre presença e representação. O fundamental é criar um espaço-tempo subjuntivo no qual é possível produzir uma presença condicional. O ritual é sem dúvida um "jogo sério", como disse Bateson. Mas isto não significa que deva ser apenas levado a sério, pois deve também ser tomado como jogo - um jogo que promove a suspensão da descrença, tornando possível que um duplo (a efígie) indexe um outro duplo (a akuãpe), sem que eles se tornem, no entanto, idênticos.

Pouco antes das primeiras luzes da manhã, os últimos cantores instam o falecido a partir em paz e não mais voltar. O fogo é extinto, as efígies abandonadas. É hora de despertar os vivos. Visitantes e anfitriões se reúnem na praça. A luta começa. Para muitas pessoas este é o ápice da festa e a razão para dela participarem. Finamente decorados e em movimentos ponderados, os donos do ritual presidem aos combates, garantindo que deles não resulte nenhum conflito. Pintados de preto e reluzentes graças ao óleo de pequi, os lutadores movimentam-se ferozmente, exibindo seus corpos de jaguar e sua capacidade para a violência. Uma vez findo o combate, contudo, devem logo mostrar uma disposição pacífica - lutadores experientes mudam de expressão facial em um piscar de olhos, abrindo um largo sorriso e abraçando o oponente. Pouco antes do meio-dia, acompanhados por meninas saindo da reclusão, os donos despedem-se formalmente dos chefes convidados. Todos partem, a praça se esvazia. As efígies são lançadas descuidadamente ao solo e, mais tarde, descartadas no lago. 


\section{Memória e nome}

A efígie de Quarup não representa uma condição humana genérica. Ele indexa uma condição específica - a do chefe - ao mesmo tempo em que é o seu ícone. A evocação mimética é construída em vários níveis: a efígie recebe os ornamentos de um dignitário, é ereta e imóvel como um chefe ao presidir um ritual, além de ser feita da mesma matéria: a madeira do umiri. Efígies figuram, assim, o corpo de chefes passados, presentes e futuros, produzindo uma imagem da continuidade das linhas de chefia. No entanto, como diria Kantorowitz, o corpo dos chefes não é um, mas dois.

Como vimos, chefes não são apenas análogos ao tronco do umiri, são também jaguares familiarizados por sua própria comunidade, a qual eles contêm em seus corpos magnificados. Um chefe é um corpo coletivo contendo os seus seguidores, aos quais ele se dirige como "crianças". Todas as outras distinções são eclipsadas para que ele apareça como uma singularidade inclusiva, uma pessoa magnificada. Antes de ser um representante, o chefe é a forma pela qual uma pluralidade é constituída como uma imagem singular para outros (no caso, para outros povos xinguanos convidados, mas hoje também para os brancos em diversos contextos interétnicos).

Em todas essas ocasiões, os chefes portam seus ornamentos exclusivos de jaguar, com uma única exceção, porém: durante o Quarup, nem eles, nem as efígies podem receber qualquer um desses adornos. O pai-efígie e seu filho-dono-do-ritual devem aparecer aí como pura imagem vegetal de continuidade, como suportes verticais de um povo, isto é, como esteios - termo, aliás, pelo qual se costuma chamá-los: kukiho, "nosso esteio". Se efígie e dono aparecem sob forma vegetal, a parte-jaguar dessa linha de chefia surge, idealmente, na figura do neto, que deverá estar presente na arena de luta. Não à toa, quando os donos do ritual convocam os jovens para lutar, usam como vocativo a expressão "neto de temido-respeitado" (itsanginhü higü). Em um Quarup, portanto, temos a imagem simultânea de uma linha composta pelo avô-efígie, o pai-dono e o neto-lutador.

Do que é feita essa continuidade? De instituições, normas, direitos ou propriedades? Embora se possa argumentar que há no Alto Xingu um conjunto difuso de direitos e propriedades rituais transmissíveis e, inclusive, que há certa institucionalização da forma "Casa" (sensu Lévi-Strauss), entendo que essa continuidade é feita, antes, de traços mnemônicos produzidos por eventos rituais e postos em circulação por meio de nomes magnificados, transmitidos de avós para netos. A expectativa é que filhos sucedam a seus pais na chefia - e isto tende a ocorrer sempre que os azares biográficos não o impeçam. Afinal, um grande chefe está em condições privilegiadas 
para "fazer" (-üi) anetü seu primogênito, patrocinando um ritual para furar sua orelha, mantendo-o em longa reclusão, ensinando-lhe a "fala de chefe" (anetü itaginhu), acompanhando-o quando ele "for sobre o banco" (tagahuhongo), e assim por diante. O filho é um "substituto" (itakongo) efetivo do pai - dir-se-ia que onde se vê o filho se vê o pai - e é muito comum o filho cumprir funções rituais no lugar do genitor.

Se o filho é o substituto ritual do pai, o neto é o substituto nominal do avô, que pode inclusive referir-se a ele como "meu nome" (uititü): "Venha ver meu nome", disse-me certa vez um amigo cujo neto acabara de nascer. Entre os Kuikuro, os nomes têm uma existência que antecede e sucede àquele que os porta em determinado momento. São signos anexados a diferentes indivíduos através do tempo, funcionando como pontos de ligação entre gerações alternas. Sempre que me fala de sua ascensão à chefia, Afukaká, o principal chefe kuikuro nos últimos 40 anos, lembra-se de dois fatos: de um lado, fizera certa fama como lutador e, de outro, como primeiro neto, portava o nome mais prestigioso de seu falecido avô, que fora chefe. É a memória nominal que o fez, como costuma dizer, "ser olhado pela comunidade".

Nomes magnificados ligam mais de uma biografia, estendendo-se de volta ao passado e em direção ao futuro. O nome da efígie - o X na expressão $\mathrm{X}$-hutoho - não é, ademais, o nome que o falecido portava no momento de sua morte, mas sim o seu nome mais famoso, aquele pelo qual ficara "falado" (tikaginhü), ainda como um jovem adulto. Normalmente, quando de sua morte, esse nome famoso já terá sido transmitido a seu neto mais velho, que poderá estar, inclusive, lutando na praça. Uma linha de chefia resulta assim da substituição dos genitores pelos filhos como equivalentes rituais, e dos avós pelos netos enquanto portadores de um mesmo nome.

A efígie do Quarup exprime, portanto, mais do que a relação um a um entre um artefato e uma pessoa. Se tomarmos todo o ciclo ritual, o falecido aparece no início como um jaguar que contém pessoas e, no final, como um tronco superdecorado que indexa chefes passados, presentes e futuros de mesmo nome; ou mais exatamente, indexa nomes, cuja história se inscreveu no corpo de pessoas fabricadas como chefes e fincados no solo da memória coletiva como um tronco efigial.

\section{Conclusão}

Permitam-me concluir. Comecei com um sobrevoo da pré-história xinguana e do processo de formação de sua constelação multiétnica e plurilíngue. Sugeri que seu desenvolvimento fundou-se em um sistema político-ritual, que passou a constituir a língua franca da região. Em seguida, mostrei como esse sistema articula o xamanismo à autoridade política, não 
porque os chefes são necessariamente xamãs, mas porque a vida ritual faz com que as relações de maestria entre humanos, e entre humanos e alterumanos intersectem-se necessariamente. Analisei, ainda, quem é o chefe e como alguém se torna um chefe no Alto Xingu, mostrando como a genealogia se transforma em prestígio através de atos de alimentação e da construção ritual de um corpo jaguarizado. Voltei-me então a outro aspecto da chefia: a sua associação com as qualidades materiais de uma árvore chamada umiri. Ao narrar o mito axial do Alto Xingu, que explica a origem da mortalidade e do Quarup, apontei para a dupla constituição animal e vegetal dos chefes. Passei, então, para o próprio ritual do Quarup, focalizando a desjaguarização do morto e sua transformação em uma efígie de madeira. Descrevi esse processo como um movimento em direção à ancestralidade, na qual emerge uma imagem de continuidade intergeracional de linhas e nomes prestigiosos. Em seguida, centrei-me na efígie enquanto artefato, descrevendo seu caráter mimético e sua capacidade de atrair e convocar uma presença. Ao fazer isso, busquei fundar pragmaticamente a animação do artefato, indicando que o recurso às dicotomias corpo e alma ou presença e representação não resolvem o "mistério da animação". O que se dá a ver, ao contrário, é um complexo jogo de duplicações, de dobras sobre dobras, que produzem uma zona de indiscernibilidade entre o artefato e o morto. Por fim, voltei ao problema da continuidade e da memória, perguntando-me de que elas são feitas, de forma a evitar uma leitura funcionalista ou normativa do material xinguano.

Agora, permitam-me propor uma última questão a fim de livrar-me do insistente fantasma da coerção e, assim, definir melhor a agência do chefe: em que consiste, afinal, a autoridade de um chefe xinguano? Seria simples derivar o termo "autoridade" da noção de autor, que costumamos glosar como "causa de algo" ou aquele que "faz ou cria algo". Esta leitura francamente ativa não é de fácil aplicação aos chefes xinguanos, cujos atos dependem de pedidos prévios da comunidade, de tal modo que sua autoridade reside antes na capacidade de extrair ações de outros do que ser o seu próprio autor. São sempre os outros que lhe pedem para furar a orelha do filho, para que seja dono de um ritual, para construir sua casa, para enterrá-lo na praça, para ser comemorado em um Quarup. Parafraseando Strathern, esta é a coerção: fazer as pessoas agirem tendo o chefe sempre em mente. ${ }^{16}$

Há, porém, um outro fio etimológico que podemos perseguir e que associa auctor a augere: o autor é aquele que "faz crescer" e sua autoridade consiste de uma capacidade incremental. Um chefe xinguano é imaginado como nutriz de seu povo, como responsável por seu crescimento, como motivo de as pessoas permanecerem unidas em uma mesma aldeia. Esse 
incremento se dá a ver pelo número de pessoas que lá vivem e de convidados que comparecem às suas festas, mas também é tornado tangível por todos os corpos materiais que lhe são atribuídos: a sua casa, a sua praça, a sua aldeia e, hoje, também seus tratores, caminhões e outros bens. Uma economia político-ritual da grandeza, diria Sahlins, mas, nesse caso, em plena Amazônia.

Essa economia parece ser funcional em diferentes escalas: reduzi-la drasticamente (como ocorreu no século 20) ou aumentá-la geometricamente (como ocorreu no século 13) não parece mudar o seu padrão básico de funcionamento. Por isso, para terminar, convido-os a projetarem-se, sem qualquer rigor metodológico, de volta ao passado. Tentem imaginar o que ali se passava ao alvorecer do período galáctico. Aumentem a escala em dez, talvez vinte vezes. Agora, ponham-se em uma dessas estradas de terra, acompanhados de várias centenas de pessoas pintadas, caminhando em direção a uma magnífica aldeia fortificada. Ao fundo, já se divisa a paliçada, ao longe já se escuta o som das flautas e dos cantos que animam a praça. O coração ferve, a respiração se agita. Bem vindos ao Alto Xingu.

\section{Notas}

* Com pequenas correções, esta é a minha conferência para promoção a titular, proferida em 21 de novembro de 2016, no Museu Nacional, Rio de Janeiro. Decidi manter sua forma oral, acrescentando-lhe algumas notas incontornáveis. Agradeço à banca formada por Luiz Fernando Dias Duarte, Roberto DaMatta, Manuela Carneiro da Cunha, Sylvia Caiuby Novaes e Ronaldo Vainfas. Uma primeira versão deste texto foi apresentada na conferência Dumbarton Oaks "Sacred Matter: Animism and Authority in the Pre-Columbian Americas", organizada por Steven Kosiba, John Janusek e Tom Cummins, em Washington, outubro de 2016. Agradeço aos três colegas pelo honroso convite. Agradeço também a Aparecida Vilaça, Luiz Costa, Kleyton Rattes e Messias Basques pela leitura crítica e generosa do texto. Contei, ainda, com o luxuoso apoio linguístico de Bruna Franchetto, Mara Santos, Mutuá Mehinaku e Sergio Meira - a todos, o abraço de sempre. Nas camadas estratigráficas mais profundas deste trabalho, corre uma longa conversa, iniciada em 1992, com Mike Heckenberger. Na pessoa do cacique Afukaká, agradeço aos Kuikuro pela gentileza e convívio de quase 20 anos. A maior parte da pesquisa de campo foi financiada pelo CNPq e pela Faperj, às quais expresso meu reconhecimento na esperança de que venham a se reerguer um dia.

1 Desenvolvi pesquisa entre os Parakanã de 1988 a 1995, retornando para outros fins em 1996, 1999, 2014 e 2015. Desde 1998, venho trabalhando no Alto Xingu com os Kuikuro. 
2 Refiro-me aqui ao famoso dito de Pero Magalhães Gandavo, para quem aos Tupinambá faltariam lei, fé e rei; ao modelo tipológico do HSAI, organizado por J. Steward, bem como à caracterização clastriana das sociedades indígenas como contra (e não sem) estado.

3 Baseio-me aqui nos trabalhos de Heckenberger e equipe (ver, entre outros, Heckenberger 2005; Heckenberger et al. 2003, 2008).

4 Sobre esse processo, veja-se Menezes Bastos (1983), Franchetto e Heckenberger (2001), Fausto, Franchetto e Heckenberger (2008) e Franchetto (2011).

5 Algumas evidências arqueológicas sugerem que os Karib entraram na região no século 16 e foram incorporados ao sistema no final do período galático. Em relação aos Yawalapiti é possível que já fizessem parte do sistema regional, habitando mais ao norte, e tenham ficado isolados após o seu declínio.

6 Sobre os rituais altoxinguanos, há inúmeros trabalhos. As principais monografias são as de Agostinho (1974), Piedade (2004), Mello (2005), Barcelos Neto (2008), Penoni (2010), Menezes Bastos (2013) e Guerreiro (2015). Analiso vários rituais kuikuro em meu novo livro, provisoriamente intitulado Artefeitos: Imagem, agência e ritual na Amazônia indígena.

7 Baseio-me aqui nas ideias de Luiz Costa (2010, 2017 - ver também Fausto e Costa 2013).

8 Os melhores dados sobre a chefia xinguana encontram-se em Heckenberger (2005), Barcelos Neto (2008), Mehinako (2010) e Guerreiro (2015). Para uma discussão sobre chefia e maestria, ver Fausto (2008) e Costa (2017).

9 A identificação foi feita por Margareth Emmerich e Luci de Senna-Vale, botânicas do Museu Nacional.

10 Há várias versões desse mito na literatura. No caso dos povos karib, contamos com Basso (1987), Carneiro (1989) e Guerreiro (2015). Minha síntese baseia-se em duas gravações que realizei cotejadas com essas versões publicadas.

11 Quarup ou Kwarup é uma corruptela do termo com que os Kamayurá (Tupi) designam esse ritual: Kwaryp ("árvore-sol"). Os Arawak xinguanos o designam Kayumai, enquanto os Karib não possuem um nome exclusivo para ele, chamando- o egitsü, um termo que se aplica a todos os rituais intertribais, do qual o Quarup é o exemplar prototípico. 
12 Não conheço qualquer outra descrição do "destripar do jaguar" na literatura. É possível que seja exclusiva dos Kuikuro e, talvez, dos Matipu. As duas melhores etnografias sobre o ciclo do Quarup são a de Agostinho (1974) para os Kamayurá e a de Guerreiro (2015) para os Kalapalo. Em geral, minha interpretação coincide com aquela de Guerreiro.

13 Tomo aqui como exemplo o caso de um homem, embora o "destripar do jaguar" também ocorra quando da morte de uma mulher anetü. Contudo, mulheres são escassamente jaguarizadas durante suas vidas, pemanecendo antes como umiri, cujo protótipo é Itsangitsegu, a mãe dos gêmeos. Sobre a noção de jaguarização e de-jaguarização, ver Fausto (2007).

14 Para uma discussão mais aprofundada dos conceitos kuikuro que aparecem nesta seção, inclusive do ponto de vista linguístico, remeto a meu novo livro, em particular aos capítulos 4 e 5. Veja-se também Fausto e Penoni (2014). Para uma comparação com os Wauja, ver os trabalhos de Barcelos Neto (2008) e Piedade (2004).

15 Este parágrafo é inspirado nos trabalhos de Bateson (1972), Seligman et al. (2008), Severi (2007) e Walton (1990). Na introdução de meu novo livro, elaboro de modo mais extenso estes pontos.

16 A referência a Marilyn Strathern aqui remete a uma passagem de The Gender of the Gift (1988); já no caso de Sahlins (1990), à sua discussão sobre a economia política da grandeza no Havaí. 
AGOSTINHO, Pedro. 1974. Kwarìp. Mito e ritual no Alto Xingu. São Paulo: EPU-Edusp.

BARCELOS NETO, Aristóteles. 2008. Apapaatai: rituais de máscaras no Alto Xingu. São Paulo: Edusp/Fapesp.

BASSO, Ellen B. 1987. In favour of deceit: a study of tricksters in an Amazonian society. Tucson, AZ: The University of Arizona Press.

BATESON, Gregory. 1972. Steps to an ecology of mind: Collected essays in anthropology, psychiatry, evolution, and epistemology. San Francisco: Chandler Pub. Co.

CARNEIRO, Robert L. 1989. "To the village of the jaguars: the master myth of the upper Xingú". Antropologica, 72:3-40.

CLASTRES, Pierre. 1974. La société contre l'État: recherches d'anthropologie politique. Paris: Les Éditions de Minuit.

COSTA, Luiz. 2010. "The Kanamari body-owner. Predation and feeding in western Amazonia". Journal de la Société des Américanistes, 96(1):169192.

. 2017. The owners of kinship: asymmetrical relations in indigenous Amazonia. Chicago, Il.: University of Chicago Press.

EMMERICH, Margarete; EMMERICH, Charlotte \& VALLE, Luci de Senna. 1987. "O kuarupe: árvore do sol". Bradea - Boletim do Herbarium Bradeanum, IV(49):388-391.

FAUSTO, Carlos. 2007. "If God were a jaguar: cannibalism and christianity among the Guarani (16th-20th Centuries)". In: Carlos Fausto \& Michael J. Heckenberger (eds.), Time and memory in indigenous Amazonia: anthropological perspectives. Gainesville, Fl.: University Press of Florida. pp. 74-105.
. 2008. "Donos demais: maestria e propriedade na Amazônia". Mana: Estudos de Antropologia Social, $14(2): 280-324$. . 2017. Artefeitos: imagem, agência e ritual na Amazônia indígena. Ms.

FAUSTO, Carlos; FRANCHETTO, Bruna \& HECKENBERGER, Michael J. 2008. "Ritual language and historical reconstruction: towards a linguistic, ethnographical and archaeological account of Upper Xingu Society". In: Arienne Dwyer, David Harrison \& David Rood (eds.), Lessons from documented endangered languages. Amsterdam: John Benjamins. pp. 129-158.

FAUSTO, Carlos \& PENONI, Isabel R. 2014. "L'effigie, le cousin et le mort: un essai sur le rituel du Javari (Haut Xingu, Brésil)". Cahiers d'Anthropologie Sociale, 10:14-37.

FAUSTO, Carlos \& COSTA, Luiz. 2013. "Feeding (and eating): reflections on Strathern's 'eating (and feeding)'". Cambridge Anthropology, 31:156-162.

FRANCHETTO, Bruna (ed.). 2011. Alto Xingu: uma sociedade multilíngue. Rio de Janeiro: Museu do Índio/ Funai.

FRANCHETTO, Bruna \& HECKENBERGER, Michael (eds.). 2001. Os povos do Alto Xingu: história e cultura. Rio de Janeiro: Editora UFRJ.

GANDAVO, Pero de Magalhães de. 1980 [1576]. História da província de Santa Cruz. São Paulo: Itatiaia / Edusp.

GELL, Alfred. 1999. "Vogel's net: traps as artworks and artworks as traps". In: E. Hirsch (ed.), The art of anthropology: essays and diagrams. London: The Athlone Press. pp. 187-214.

GUERREIRO, Antonio. 2015. Ancestrais e suas sombras: uma etnografia da chefia kalapalo e seu ritual mortuário. Campinas, SP: Editora Unicamp. 
HECKENBERGER, Michael J. 2005. The ecology of power: culture, place, and personhood in the southern Amazon, A.D. 1000-2000. New York: Routledge. et. al. 2003. "Amazonia 1492: pristine forest or cultural parkland?". Science, 301(5.640):1710-1714. et. al. 2008. "Pre-Columbian urbanism, anthropogenic landscapes, and the future of the Amazon". Science, 321:1214-1217.

KANTOROWICZ, Ernst H. 1981.The king's two bodies: a study in mediaeval political theology. Princeton, NJ: Princeton University Press.

LÉVI-STRAUSS, Claude. 1984. "La notion de maison (année 1976-1977)". In: Paroles données. Paris: Plon. pp. 189-194.

MEHINAKO, Makaulaka. 2010. "A hereditariedade tradicional da função de cacique entre os Mehinako. In: Bruna Franchetto (ed.), Pesquisas indígenas na universidade. Rio de Janeiro: Museu do Índio/Funai. pp. 117-148. MELLO, Maria Ignez Cruz. 2005. Iamurikuma: música, mito e ritual entre os Wauja do Alto Xingu. Tese de Doutorado, Universidade Federal de Santa Catarina.

MENEZES BASTOS, Rafael José de. 1983. "Sistemas políticos, de comunicação e articulação social no Alto Xingu". Anuário Antropológico, 81:3-58. . 2013. A festa da jaguatirica: uma partitura crítico-interpretativa. Florianópolis: Editora UFSC.
PENONI, Isabel. 2010. Hagaka: ritual, performance e ficção entre os Kuikuro do Alto Xingu. Dissertação de Mestrado, PPGAS-Museu Nacional, Universidade Federal do Rio de Janeiro.

PIEDADE, Acácio Tadeu de Camargo. 2004. O canto do Kawoká: música, cosmologia e filosofia entre os Wauja do Alto Xingu. Tese de Doutorado em Antropologia, Universidade Federal de Santa Catarina.

SAHLINS, Marshall. 1990. "The political economy of grandeur in Hawai'i from 1810 to $1830 "$. In: E. Ohnuki-Tierney (ed.), Culture through time: anthropological approaches. Stanford, CA: Stanford University Press. pp. 26-56. SELIGMAN, Adam B.; WELLER, Robert P.J.; PUETT, Michael \& SIMON, Bennett. 2008. Ritual and its consequences an essay on the limits of sincerity. Oxford: Oxford University Press.

SEVERI, Carlo. 2007. Le principe de la chimère: une anthropologie de la mémoire. Paris: Éditions Rue d'UlmENS/ Musée du quai Branly.

STEWARD, Julian H. 1948. Handbook of South American Indians. Washington: Smithsonian Institution/ Bureau of American Ethnology. 7 vols.

STRATHERN, Marilyn. 1988. The gender of the gift: problems with women and problems with society in Melanesia. Berkeley: University of California Press.

WALTON, Kendall L. 1990. Mimesis as make-believe: on the foundations of the representational arts. Cambridge, Mass.: Harvard University Press. 